\title{
Effects of Submerged Vegetation on Water Clarity Across Climates
}

\author{
Sarian Kosten, ${ }^{1 *}$ Gissell Lacerot, ${ }^{1,2}$ Erik Jeppesen, ${ }^{3,4}$ David da Motta \\ Marques, ${ }^{5}$ Egbert H. van Nes, ${ }^{1}$ Nestor Mazzeo, ${ }^{2}$ and Marten Scheffer ${ }^{1}$
}

\begin{abstract}
${ }^{1}$ Department of Aquatic Ecology and Water Quality Management, Wageningen University, P.O. Box 47, 6700 AA Wageningen, The Netherlands; ${ }^{2}$ Departamento de Ecología, Facultad de Ciencias, Universidad de la República, Iguá 4225, CP 11400 Montevideo, Uruguay; ${ }^{3}$ Department of Freshwater Ecology, National Environmental Research Institute, Aarhus University, Vejlsøvej 25, 8600 Silkeborg, Denmark; ${ }^{4}$ Department of Plant Biology, Aarhus University, Ole Worms Allé 135, 8000 Aarhus, Denmark; ${ }^{5}$ IPH-Universidade Federal do Rio Grande do Sul, Av. Bento Gonçalves, 9500, C.P. 15029, Porto Alegre 91501-970, Brazil
\end{abstract}

\begin{abstract}
A positive feedback between submerged vegetation and water clarity forms the backbone of the alternative state theory in shallow lakes. The water clearing effect of aquatic vegetation may be caused by different physical, chemical, and biological mechanisms and has been studied mainly in temperate lakes. Recent work suggests differences in biotic interactions between (sub)tropical and cooler lakes might result in a less pronounced clearing effect in the (sub)tropics. To assess whether the effect of submerged vegetation changes with climate, we sampled 83 lakes over a gradient ranging from the tundra to the tropics in South America. Judged from a comparison of water clarity inside and outside vegetation beds, the vegetation appeared to have a similar positive effect on the water clarity across all climatic regions studied. However, the local clearing effect of vegetation decreased steeply with the contribution of humic substances to the underwater light attenuation. Looking at
\end{abstract}

Received 11 February 2009; accepted 8 July 2009;

published online 25 September 2009

Author Contributions: Sarian Kosten participated in field campaign, designed study, performed research, analyzed data, contributed new methods, and wrote paper. Gissell Lacerot, Erik Jeppesen, David da Motta Marques, Egbert H. van Nes, Nestor Mazzeo, and Marten Scheffer participated in field campaign, contributed ideas for the manuscript, and commented on drafts.

*Corresponding author; e-mail: sarian.kosten@wur.nl turbidity on a whole-lake scale, results were more difficult to interpret. Although lakes with abundant vegetation $(>30 \%)$ were generally clear, sparsely vegetated lakes differed widely in clarity. Overall, the effect of vegetation on water clarity in our lakes appears to be smaller than that found in various Northern hemisphere studies. This might be explained by differences in fish communities and their relation to vegetation. For instance, unlike in Northern hemisphere studies, we find no clear relation between vegetation coverage and fish abundance or their diet preference. High densities of omnivorous fish and coinciding low grazing pressures on phytoplankton in the (sub)tropics may, furthermore, weaken the effect of vegetation on water clarity.

Key words: transparency; vegetation; feedbacks; humic lakes; climate; alternative state theory; South America; grazing pressure; fish.

\section{INTRODUCTION}

Temperate shallow lakes tend to have two contrasting states over a range of conditions: a clear state dominated by aquatic vegetation or a turbid state (Jeppesen and others 1990; Moss 1990; Scheffer 1990; Scheffer and others 1993). This phenomenon has been explained by the alternative stable state theory (Scheffer and others 1993). The backbone of this theory is the positive feedback 
between vegetation and water clarity: vegetation enhances water clarity and clearer water promotes vegetation growth. Several mechanisms may contribute to the impact of submerged vegetation on water clarity. Vegetation may provide a refuge for zooplankton (Timms and Moss 1984; Schriver and others 1995); prevent resuspension and promote sedimentation of suspended matter (Barko and James 1998; Madsen and others 2001); compete, together with periphyton, for nutrients and light with phytoplankton (Ozimek and others 1990); or the vegetation may excrete allelopathic substances inhibiting growth of phytoplankton (Gross and Sütfeld 1994). Different combinations of these mechanisms have been held responsible for the higher water transparency in the presence of plants.

How strong the different physical, chemical, and biological water clearing mechanisms are and how they interact under different conditions is still unclear. Especially differences in biological interactions in (sub)tropical and temperate lakes may result in a less pronounced clearing effect in the (sub)tropics (Jeppesen and others 2007a, b; Meerhoff and others 2007b). Zooplankton, for instance, tends to be much smaller in warmer regions (Gillooly and Dodson 2000) which decreases their filtering capacity and likely weakens the top down control on phytoplankton. Furthermore, the high density of continuously reproducing omnivorous fish (generally small-sized species) in the (sub)tropics and their association with submerged vegetation (Sazima and Zamprogno 1985; Conrow and others 1990; Mazzeo and others 2003) decreases the potential control of phytoplankton by zooplankton (Jeppesen and others 2005; van Leeuwen and others 2007). These aspects could weaken or eliminate the zooplankton-mediated part of the water clearing effect of aquatic vegetation (Meerhoff and others 2007b).

Fish may also influence water clarity by resuspending sediment, by increasing nutrient cycling from the sediment to the water column (Lammens 1988), or by grazing on aquatic vegetation (Hansson and others 1987). Differences in diet and feeding behavior among fish in cool and warmer lakes may therefore also cause a difference in the water clearing effect of submerged macrophytes.

The effect of vegetation on water clarity through nutrient competition with phytoplankton may differ between climates as well. As periphyton densities tend to be lower in warmer lakes (Meerhoff and others 2007a; Bécares and others 2008), likely due to grazing by omnivorous fish (Meerhoff and others 2007a), the macrophyte-periphyton ensemble might compete less for nutrients with phytoplankton in warmer than in cooler lakes.

Insight into the water clearing effect is important not only from a theoretical point of view but also for understanding the probability of success of management options in different climate zones (Jeppesen and others 2007a). For instance, effects of a temporary fish stock reduction ('biomanipulation') can be long lasting if a self-stabilizing vegetated state is reached. Also, the positive feedback resulting from the clearing effect is important for lake restoration measures such as inoculating lakes with vegetation (for example, Hilt and others 2006) or protecting plants from grazing by waterfowl (Søndergaard and others 1996) with the aim to create favorable conditions for plants to recover.

The effect of vegetation on water clarity can be studied experimentally using enclosures with and without plants (Hasler and Jones 1949; Schriver and others 1995). Although this is a straightforward approach, results remain difficult to translate to whole-lake situations where fish and wind influences are different. Alternatively, the effect of vegetation on clarity can be evaluated by comparing individual lakes in years with vegetation dominance and in years with algal dominance (for example, Meijer and Hosper 1997) or by comparing water clarity among lakes with different macrophyte coverages (for example, Jeppesen and others 1990; Bachmann and others 2002). Obviously, there remains an issue of causality in such studies, as one can never be sure to which extent clarity is the cause or the effect of differences in vegetation abundance. Another common way to evaluate the effect of vegetation on transparency is to compare water clarity between open water and vegetation stands within a lake (for example, Pokorny and others 1984; Jones 1990). Although this is a straightforward approach to assess local effects, it does not capture the potential effects of vegetation beds on open water characteristics, occurring, for instance, through alteration of the fish community or through the promotion of large herbivorous zooplankton species that may migrate to the open water (Timms and Moss 1984; Jeppesen and others 1998).

Here, we explore the potential effect of climate on the capacity of submerged plants to clear the water, by comparing water clarity and seston characteristics in lakes with and without abundant macrophyte growth as well as inside and outside vegetation beds in 83 lakes across a climatic gradient ranging from tundra to tropical regions in South America. 


\section{Materials AND Methods}

\section{Study Sites}

We sampled 83 shallow lakes along a latitudinal gradient $\left(5-55^{\circ} \mathrm{S}\right)$ in South America. The lakes were classified into three groups based on the prevailing climate (New and others 2002): 'warm' sites had an average monthly air temperature above $25^{\circ} \mathrm{C}$ in at least 1 month, at 'cold' sites ground frost occurred for more than 120 days a year, and the other lake sites were classified as 'intermediate' (Figure 1). All lakes were shallow and had a surface area smaller than $2.53 \mathrm{~km}^{2}$. In every group, lakes were selected to vary as much as possible in vegetation coverage and trophic state (Table 1).

\section{Sampling}

All lakes were sampled once during summer (cold and intermediate lakes) or dry season (warm lakes) between November 2004 and March 2006 by the same team. We collected depth-integrated water samples at 20 random points in each lake. From each point sample, $2 \mathrm{l}$ were used to pool into a single large bulk sample. Subsequent subsampling for different analyses was done from the bulk sample. Filtration for various analyses was conducted directly after collection. Water and filters were then frozen until analysis. Phytoplankton

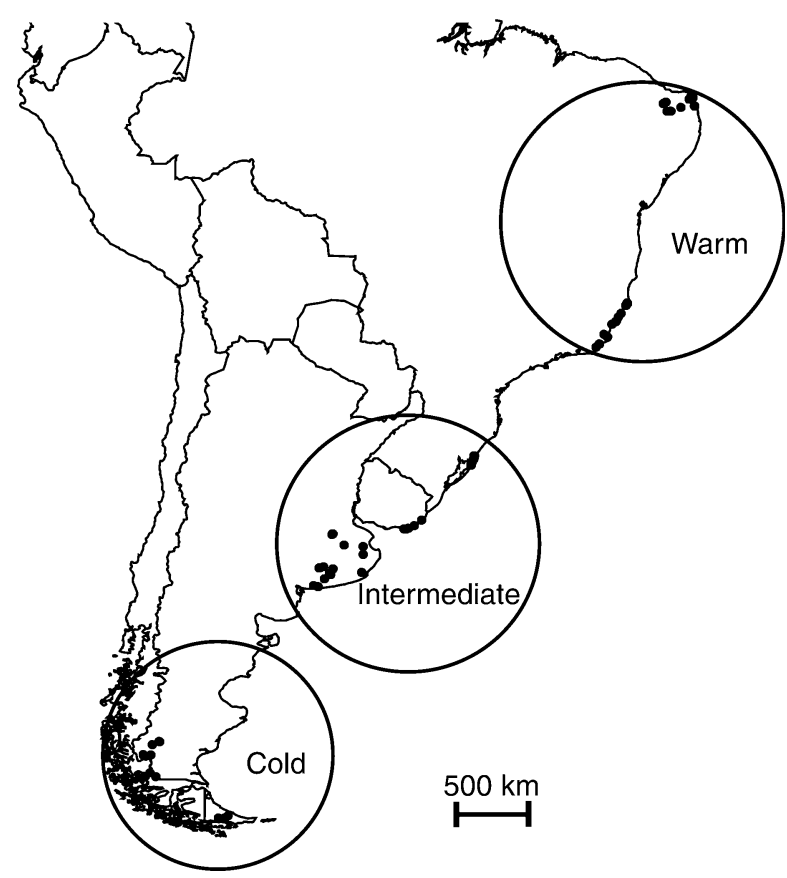

Figure 1. Location of the sampled lakes in climatologically different regions. samples were fixed in Lugol's solution. Another 21 were filtered on a $50-\mu \mathrm{m}$ sieve for quantitative zooplankton determination. The zooplankton sample was preserved in a $4 \%$ formaldehyde solution. Light measurements were conducted at different depths at noon in the center of the lake with a LICOR LI-192SA. Coverage of submerged vegetation ( $\left.\mathrm{COV}_{\text {lake }}\right)$ was estimated based on observations of vegetation presence/absence at 20 random points in the lake combined with coverage estimations of macrophytes at 13-47 points (average 22) equally distributed on 3-8 parallel transects perpendicular to the maximum length of the lake. The number of transects varied with the shape and size of the lake. Observations were made from a boat using a grapnel when water transparency was insufficient to get a clear view of the bottom. Furthermore, we measured depth and the length of the plants at each sample point along the transects.

At approximately one-third of the sample points along the transects, we measured water clarity using three different techniques: by measuring fluorescence, turbidity, and mini-disk depth. These techniques comprise different components influencing water clarity. Fluorescence gives an indication of the phytoplankton abundance, turbidity measurements include phytoplankton, detritus, and inorganic suspended solids, and the mini-disk depth is influenced by all these components plus humic substances. We determined fluorescence and turbidity using a Turner Design Handheld Fluorometer. The fluorescence channel was calibrated daily with a solid secondary standard (PN 8000-950, Turner Designs) and the turbidity channel with a 50 NTU "non-ratio" standard (GFS chemicals). If macrophytes were present, we took care not to resuspend loosely attached epiphytes. We measured the 'mini-disk depth' by filling a 0.5$\mathrm{m}$-long metal tube of $7 \mathrm{~cm}$ in diameter with water in which we submersed a black and white disk until it just disappeared. The mini-disk method allows visual quantification of water transparency in places where a Secchi disk would have hit the bottom or disappeared between the plants. Fish were sampled overnight by multimesh gillnets (Appelberg 2000; Mazzeo and others unpublished data). Data represent the average catch among nets, expressed as catch per unit effort (CPUE; individuals net ${ }^{-1} \cdot 12 \mathrm{~h}$ ).

\section{Sample Analysis}

Total phosphorus (TP) and total nitrogen (TN) concentrations were analyzed using a continuous flow analyzer (Skalar Analytical BV) following NNI 
Table 1. General Data on the Lakes Sampled

\begin{tabular}{|c|c|c|c|}
\hline & Range & Mean & Medium \\
\hline Area $\left(\mathrm{km}^{2}\right)$ & $0.09-2.53$ & 0.62 & 0.46 \\
\hline Mean depth (m) & $0.5-4.5$ & 1.8 & 1.6 \\
\hline Average air temperature during warmest month $\left({ }^{\circ} \mathrm{C}\right)^{1}$ & $8.2-28.7$ & 23.2 & 23.5 \\
\hline Number of ground frost days $\left(y^{-1}\right)^{1}$ & $0-169$ & 30 & 2 \\
\hline Conductivity $\left(\mu \mathrm{Scm}^{-1}\right)$ & $37.8-4930$ & 527 & 167 \\
\hline Total nitrogen $\left(\mathrm{mg} \mathrm{N}^{-1}\right)$ & $<0.1-25.8$ & 1.8 & 0.4 \\
\hline Total phosphorus (mg $\mathrm{P} \mathrm{l}^{-1}$ ) & $0.02-9.14$ & 0.27 & 0.10 \\
\hline Total suspended solids $\left(\mathrm{mg} \mathrm{l}^{-1}\right)$ & $2-663$ & 43 & 9 \\
\hline Chlorophyll-a $\left(\mu \mathrm{g} \mathrm{l}^{-1}\right)$ & $0.6-2889$ & 79.6 & 4.7 \\
\hline Turbidity (NTU) & $0.1-303$ & 19 & 5 \\
\hline Fluorescence $\left(\mu \mathrm{g} \mathrm{l}^{-1}\right)$ & $7 \times 10^{-2}-204$ & 5 & 1 \\
\hline Humic substances (absorption $\mathrm{m}^{-1}$ at $\lambda=380 \mathrm{~nm}$ ) & $0.3-54.2$ & 5.9 & 4.0 \\
\hline Light attenuation coefficient $\left(\mathrm{m}^{-1}\right)$ & $0.5-43.6$ & 4.6 & 2.5 \\
\hline PVI (\%) & $0-81$ & 10.5 & 0.5 \\
\hline Zooplankton biomass ( $\mu$ g Dry Weight $\mathrm{l}^{-1}$ ) & $4-4466$ & 530 & 142 \\
\hline Fish (CPUE; individuals net $\left.{ }^{-1} \cdot \mathrm{h}\right)$ & $0-168$ & 18 & 7 \\
\hline
\end{tabular}

protocols $(1986,1990)$, with the exception of the UV/persulfate destruction which was not executed beforehand but integrated in the system. Suspended solids were determined on pre-weighed $\mathrm{GF} / \mathrm{F}$ Whatman filters after drying at $105^{\circ} \mathrm{C}$ for one night. Loss on ignition $\left(3 \mathrm{~h}\right.$ at $\left.500^{\circ} \mathrm{C}\right)$ was used as a proxy for organic matter $(\mathrm{OM})$. As a measure for humic substances, spectrophotometric light absorption at $380 \mathrm{~nm}$ (Buiteveld 1995) was measured in filtered $(0.45 \mu \mathrm{m}$ S\&S) water against distilled water using a $5-\mathrm{cm}$ cuvette. Chlorophyll-a (chla) was extracted from filters (GF/C S\&S) with $96 \%$ hot ethanol, and absorbance was measured at 665 and $750 \mathrm{~nm}$ (Nusch 1980). Zooplankton taxa were counted and identified (Lacerot and others unpublished data; Kosten and others 2009a). Fish were classified according to their habitat preference (benthic, including benthic-pelagic species, or pelagic) and their diet (potentially piscivores, omnivores, periphyton feeders, and detritivores) based on literature on each species (Mazzeo and others unpublished data). We did not encounter fish with a diet of aquatic plants.

Every type of analysis was undertaken by a single person, mostly in one laboratory.

\section{Calculations and Data Analysis}

The percentage of the lake's volume filled with submerged vegetation (PVI) was determined analogously to Canfield and others (1984) The PVI of the individual sampling locations $\left(\mathrm{PVI}_{\mathrm{loc}}\right)$ was calculated by multiplying the coverage percentage by the average length of the macrophytes divided by the depth. The PVI of the entire lake ( $\left.\mathrm{PVI}_{\text {lake }}\right)$ was calculated by multiplying the area of the lake covered by macrophytes $\left(\mathrm{m}^{2}\right)$ with the average height of vegetation in the vegetated locations that were sampled $(\mathrm{m})$ divided by the total volume of the lake $\left(\mathrm{m}^{3}\right)$.

To evaluate local effects of vegetation, we compared water clarity inside and outside the vegetation beds. In lakes where the vegetation coverage allowed us to take at least two samples inside and outside the vegetation beds, we calculated the average fluorescence (in 20 lakes), turbidity (in 19 lakes), and mini-disk depth (in 10 lakes) for open water $\left(\mathrm{PVI}_{\mathrm{loc}}<30 \%\right)$ and vegetated areas $\left(\mathrm{PVI}_{\mathrm{loc}}>70 \%\right)$. Subsequently, the difference in values in the open water and the vegetated areas was expressed as a percentage of the open water values. We defined this percentage as the "water clearing effect' of the vegetation. A positive water clearing effect means that the water clarity inside the vegetation beds was higher than in the open water. We checked for correlations between the water clearing effect on the one hand and lake area, $\mathrm{PVI}_{\text {lake, }}$ concentrations of suspended solids, $\mathrm{TP}$, humic substances, chla, and fish density on the other, using Spearman rank correlation. In bi-plots, we checked for possible nonlinear relationships.

When verifying the water clearing effect of the most frequently occurring taxa of submerged species, we compared the fluorescence, turbidity, and mini-disk depth measurements at the locations of homogeneous stands $\left(\mathrm{PVI}_{\mathrm{loc}}>70 \%\right)$ with the 
average values of the open water. When a KruskalWallis test indicated differences $(P<0.05)$ among the species then a post hoc Mann-Whitney test was used to identify similarity of medians $(P>0.05)$.

Additionally, we were interested in what the enhanced water clarity meant in terms of the increase in potential colonization depth. Submerged vegetation may colonize a lake until a depth where approximately $1 \%$ of the incoming irradiance reaches the bottom (for example, Hudon and others 2000): the euphotic depth. Our estimation of how much deeper the vegetation could potentially colonize the lake by its own enhancement of the water clarity had four steps. First, we calculated the vertical light attenuation of each lake $\left(K_{\mathrm{d}}\right)$ using Lambert-Beer's law and irradiation data. Second, we used different light attenuation compounds measured in the bulk sample as independent variables describing the $K_{\mathrm{d}}$ in a multiple linear regression (analogous to Buiteveld 1995; De Lange 2000): fluorescence as a proxy for algal biomass, turbidity as a proxy for suspended solids, and humic substances as a proxy for the dissolved substances. Third, we used this model in each lake to estimate the $K_{\mathrm{d}}$ in the open water and in the vegetated area with the fluorescence and turbidity data measured in the open water and in the vegetation beds, respectively. Finally, we calculated the depth at which $1 \%$ of the surface irradiance penetrated from the calculated $K_{\mathrm{d}}$ 's using Lambert-Beer's law. We did this both in the open water and in the vegetation bed. The difference between these two depths then gives the increase in potential maximum colonization depth caused by the water clearing effect of the vegetation.

Furthermore, the multiple regression model describing $K_{\mathrm{d}}$ allowed us to determine the contribution of humic substances to the $K_{\mathrm{d}}$ simply by dividing the model term for humic substances by $K_{\mathrm{d}}$.

To evaluate the influence of submerged vegetation on whole-lake water clarity, we assessed whether PVI adds to the explained variance of $K_{\mathrm{d}}$ or OM by TP. As TP and PVI influence each other, we also checked for direct relationships between PVI, $K_{\mathrm{d}}$, and OM using linear regressions. Because fish may strongly influence the water clarity (for example, Lammens 1988; Mazumder and others 1990), we included the benthic fish CPUE as a co-variable. Additionally, we evaluated the relationship between PVI and the potential grazing pressure to obtain insight into the possible influence of PVI on water clarity using a two-way ANOVA. As an indication for the potential grazing pressure of zooplankton on phytoplankton, we used the zooplankton biomass:phytoplankton biomass ratio. We used a factor of 66 to convert chla concentrations to phytoplankton biomass (Jeppesen and others 1999).

All statistical analyses were performed using SPPS for Windows v. 15.0 (SPSS Inc., Chicago, IL, USA). Data were log transformed to approach normality; to avoid zeros, the lake's PVI was enlarged by $1 \%$ and the CPUE was increased by 1 individual net ${ }^{-1} \cdot 12 \mathrm{~h}$. Differences between groups were determined using ANOVA's. When the data were not normally distributed (ShapiroWilk $P<0.05)$, differences were assessed with Kruskal-Wallis and Mann-Whitney $U$ tests as a post hoc comparison. The Levene statistic was used to test for the equality of group variances.

\section{RESUlts}

\section{Local Effects on Transparency}

In almost all lakes, turbidity was lower inside the vegetation beds than in the open water, indicating that vegetation has a rather consistent positive effect on local water clarity (Figure 2). Also, the overall photosynthetic capacity of phytoplankton (measured as fluorescence) was often lower inside the vegetation beds than in the open water (Figure 2). There was no significant difference in these local effects of vegetation on turbidity and fluorescence among the three climate regions (one-way ANOVA, $P=0.57$ and 0.34 , respectively). Also, we did not find significant correlations between the water clearing effect (measured as difference in fluorescence or turbidity) and the variables lake area, $\mathrm{PVI}_{\text {lake, }}$ concentrations of suspended solids, TP, humic substances, chla, total fish density, and potential grazing pressure. However, we found a strong negative correlation between the clearing effect of vegetation determined with mini-disk readings and the concentration of humic substances (Spearman's $\rho=-0.81, P<0.01$ ). The clearing effect of vegetation was very small or even negative in lakes with a high content of humic substances.

Not surprisingly, the water clearing effects measured in different ways were significantly correlated (Spearman's $\rho$ varied between 0.6 and 0.8 , $P<0.05)$. The water clearing effect of different submerged vegetation taxa varied among the sampling locations. Generally, we did not find differences in the water clearing effect estimated from turbidity and mini-disk depth among the genera (Kruskal-Wallis $P=0.532$ and 0.171 , respectively). However, Egeria densa, the only species collected for the Egeria genus, appeared to have a weaker effect on phytoplankton than the other taxonomic groups (Kruskal-Wallis $P=0.041$, Figure 3 ). 


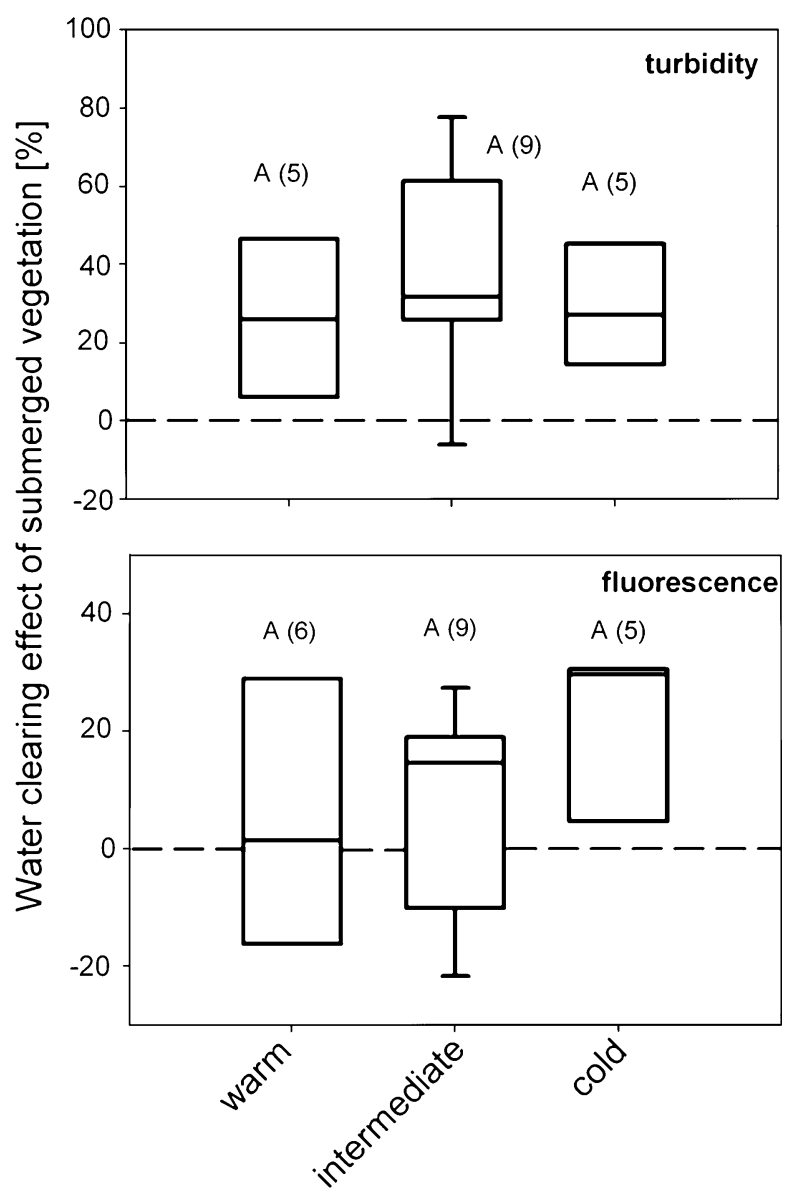

Figure 2. Water clearing effect of submerged vegetation in three different climate regions based on fluorescence and turbidity measurements (mini-disk measurements are not shown because of lack of data in the cold climate zone). Boundaries of the box plots indicate the 25th and 75 th percentile. Whiskers above and below indicate the 90th and 10th percentiles. Capital letters indicate groups with significantly similar medians. The number of data points is given in parentheses.

\section{Effect on Light Climate}

A linear regression with the light attenuation coefficient $\left(K_{\mathrm{d}}\right)$-measured in the center of the la$\mathrm{ke}$-as the dependent variable, and fluorescence (fluo in $\mu \mathrm{g}^{-1}$ ), turbidity (turb in NTU), and humic substances (humic in $\mathrm{m}^{-1}$ ) -measured in the bulk water sample-as the independent variables resulted in the following model (explaining $92 \%$ of the variance, $P<0.0001, n=20$ ):

$$
K_{\mathrm{d}}=1.05+0.051 \text { fluo }+0.101 \text { turb }+0.148 \text { humic }
$$

Using this model, the relative contribution of humic substances to the $K_{\mathrm{d}}$ was estimated to range

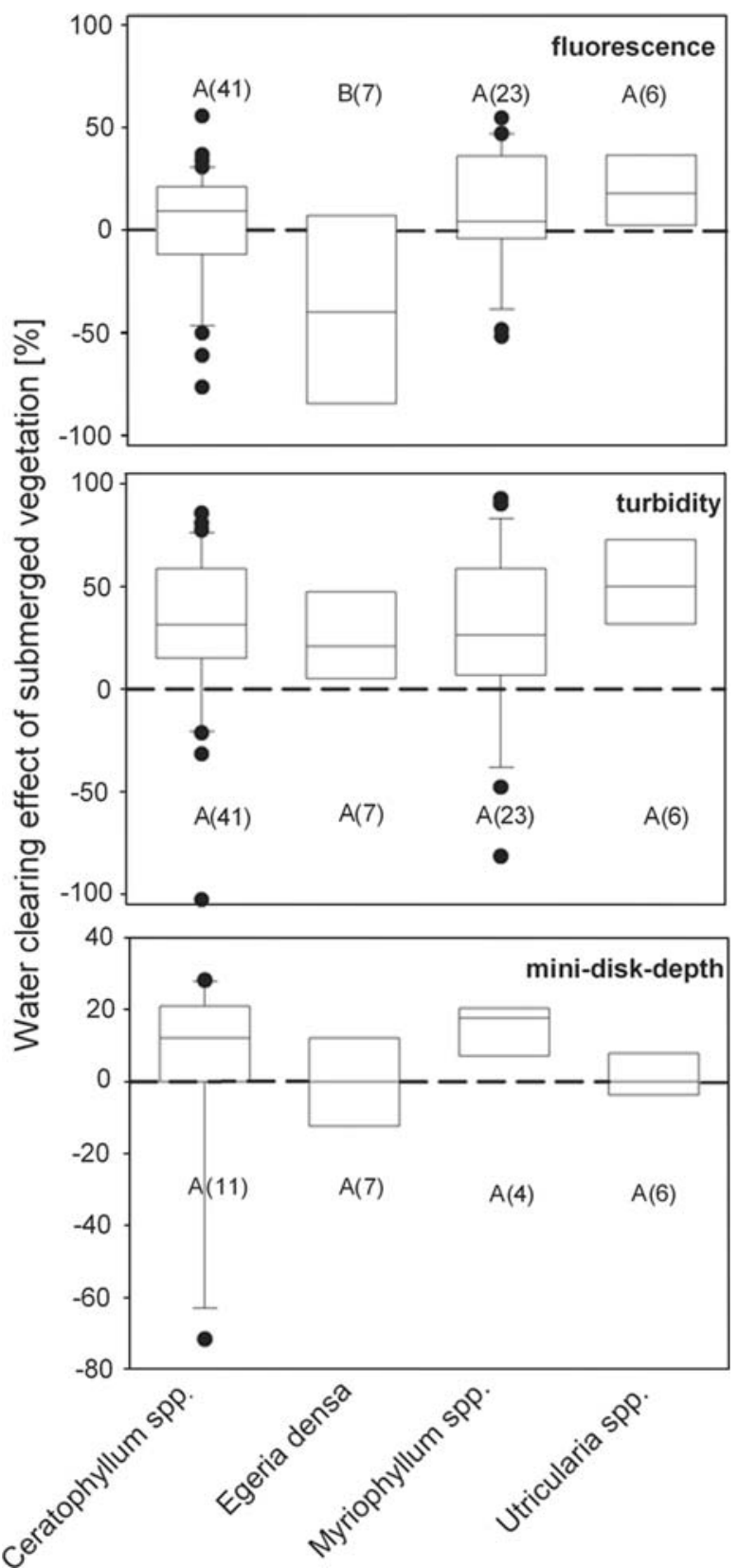

Figure 3. Water clearing effect of different genera based on fluorescence, turbidity, and mini-disk measurements. Black dots are outlying points. See Figure 2 for details.

between $10 \%$ and $66 \%$ (Figure 4). Using fluorescence and turbidity data measured inside and outside the vegetation bed, the model allows us to estimate the effect of vegetation on the euphotic depth, suggesting a potential increase of approximately $60 \mathrm{~cm}$. The estimated effect of vegetation on euphotic depth was negatively correlated to the humic contribution to the $K_{\mathrm{d}}$ (Figure $4, R^{2}=0.38$, $P=0.005)$. 


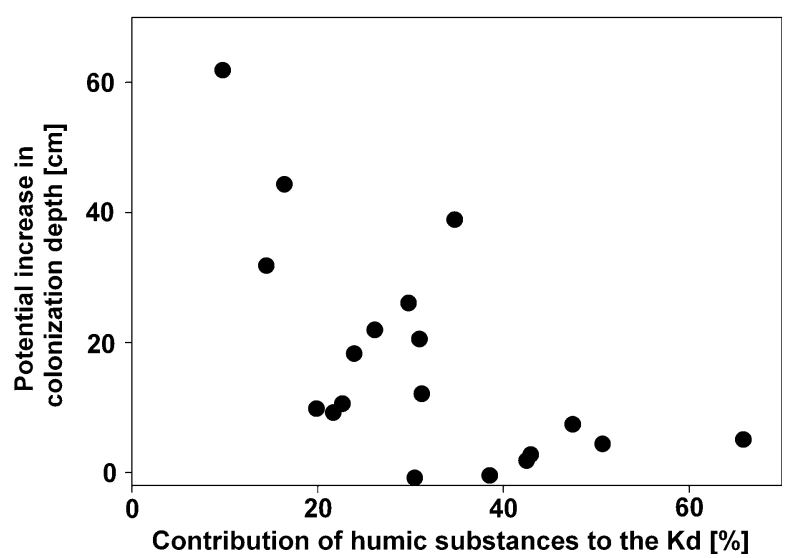

Figure 4. Calculated increase in maximum colonization depth due to the water clearing effect of submerged vegetation in lakes where the light attenuation is influenced by humic substances in different degrees. In humic lakes, submerged vegetation has a relatively small influence on the turbidity. The vegetation, therefore, does not enhance the light availability and does hardly increase its maximum colonization depth.

\section{Whole-Lake Comparisons}

Lakes with abundant vegetation $\left(\mathrm{PVI}_{\text {lake }}>30 \%\right)$ were generally clearer, as indicated by low $K_{\mathrm{d}}{ }^{\prime} \mathrm{s}$ (measured in the center of the lake), low OM, and low chla concentrations (both measured in the bulk water sample taken at 20 points across the lake), whereas sparsely vegetated lakes $\left(\mathrm{PVI}_{\text {lake }}<30 \%\right)$ had a larger range of turbidities (Figures 5 and 6). The variance in both $K_{\mathrm{d}}$ and OM significantly differed between abundant and sparsely vegetated lakes $(P<0.05)$. In linear regressions, $K_{\mathrm{d}}$ and OM were strongly related to TP and TN (Table 2, Figure 5). PVI and the lake area did not significantly enhance this relationship, but the potential grazing pressure did (Table 2). PVI was not significantly related to $K_{\mathrm{d}}$ measured in the center of the lake. However, PVI alone, or in combination with TN, did significantly explain part of the variance in $\mathrm{OM}$ (Table 2). The slope of the relationship between PVI and OM was not significantly different among the climate regions (ANCOVA: PVI $\times$ climate interaction term $P>0.05)$. The benthic and detrivorous fish density did not significantly increase the explained variance in OM nor in $K_{\mathrm{d}}$.

In all climate regions, the potential grazing pressure of zooplankton was generally higher in lakes with abundant vegetation, although the difference was only significant in the intermediate region (Figure 7a). Comparison among the climate regions indicated that the colder lakes had the highest potential grazing pressure (Figure 7a). These lakes also had lower densities of omnivorous fish, that is potentially zooplanktivorous fish, than lakes in the other climate regions (Figure 7b). In the cold lakes with high potential grazing pressures and high PVI, the chla concentration was also generally lower than expected solely from the TP concentration (Figure 6). Similar results are obtained when using TN concentrations (not shown). Using a different approximation of the potential grazing pressure in which only cladocerans and herbivorous copepods are taken into account, assuming that they ingest $100 \%$ and $50 \%$ of their biomass per day, respectively (Jeppesen and others 1994), did not considerably change the outcome of the analysis (not shown).

The fish community did not vary substantially between lakes with and without abundant vegetation growth. The percentage of potentially piscivorous fish was not significantly correlated to PVI in any climate region $(P$ values were 0.284 , 0.252 , and 0.905 in the warm, intermediate, and cold region, respectively). Furthermore, we did not find an increase in the proportion of benthic fish with a decrease in PVI in the warm and cold region $(\rho=0.04, \quad P=0.41$ and $\rho=-0.57, \quad P=0.07$, respectively). In the intermediate region, we even found an increase in the percentage of benthic fish with an increase in PVI $(\rho=0.54, P<0.001)$. Furthermore, we did not find a correlation between the CPUE of benthic fish and the OM concentration

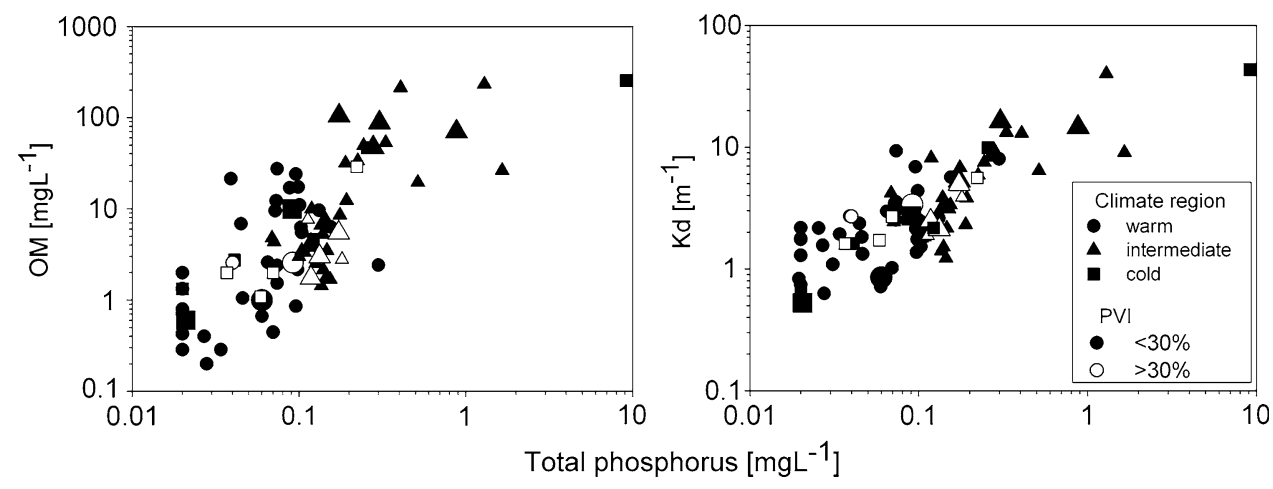

Figure 5. (left) Organic matter concentration (OM) and (right) light attenuation $\left(K_{\mathrm{d}}\right)$ in lakes with scarce or abundant vegetation growth along a TP concentration gradient in lakes in different climate regions. The larger symbols depict lakes larger than 100 ha. 


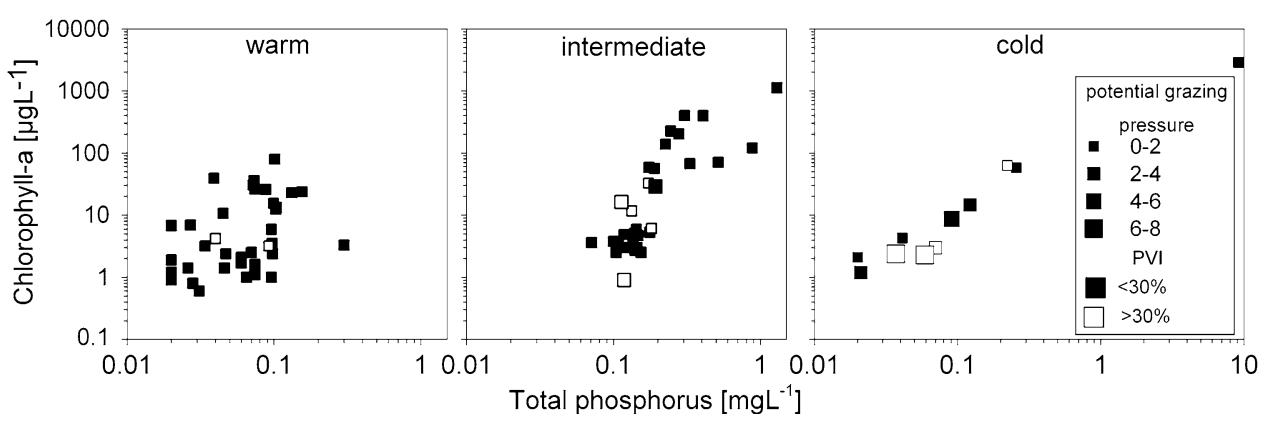

Figure 6. Chlorophyll-a concentration along a TP concentration gradient in lakes with various degrees of potential grazing pressure (zooplankton:algal biomass ratio) in the warm, intermediate, and cold climate region, with scarce (PVI $<30 \%$ ) or abundant (PVI > 30\%) vegetation growth.

Table 2. Models Describing Lake Chlorophyll-a (chla) Concentration, Light Attenuation $\left(K_{\mathrm{d}}\right)$, and Organic Matter Concentration (OM) by Total Phosphorus Concentration (TP), Total Nitrogen Concentration (TN), Lake Volume Filled with Submerged Vegetation (PVI), and Potential Grazing Pressure (PGP) of Zooplankton on Phytoplankton

\begin{tabular}{lll}
\hline Dependent & Model & $R_{\text {adj }}^{2}$ \\
\hline $\log \left(K_{\mathrm{d}}\right)$ & $-0.90^{(<0.001)}+0.68 \log (\mathrm{TP})^{(<0.001)}$ & 0.59 \\
& $-0.64^{(<0.001)}+0.65 \log (\mathrm{TP})^{(<0.001)}-0.09 \log \left(\mathrm{PGP} \times 10^{3}\right)^{(0.038)}$ & 0.61 \\
& $-0.93^{(<0.001)}+0.50 \log (\mathrm{TN})^{(<0.001)}$ & 0.62 \\
$\log (\mathrm{OM})$ & $-1.81^{(<0.001)}+1.25 \log (\mathrm{TP})^{(<0.001)}$ & 0.54 \\
& $-1.16^{(0.002)}+1.19 \log (\mathrm{TP})^{(<0.001)}-0.22 \log \left(\mathrm{PGP} \times 10^{3}\right)^{(0.011)}$ & 0.57 \\
& $0.86^{(<0.001)}-0.32 \log (\mathrm{PVI})^{(0.008)}$ & 0.09 \\
& $-2.02^{(<0.001)}+0.98 \log (\mathrm{TN})^{(<0.001)}$ & 0.65 \\
& $-1.85^{(<0.001)}+0.96 \log (\mathrm{TN})^{(<0.001)}-0.23 \log (\mathrm{PVI})^{(0.001)}$ & 0.70 \\
$\log (\mathrm{chla})$ & $-1.70^{(<0.001)}+1.31 \log (\mathrm{TP})^{(<0.001)}$ & 0.59 \\
& $-0.58^{(0.123)}+1.20 \log (\mathrm{TP})^{(<0.001)}-0.37 \log \left(\mathrm{PGP} \times 10^{3}\right)^{(<0.001)}$ & 0.05 \\
& $1.08^{(<0.001)}-0.31 \log (\mathrm{PVI})^{(0.023)}$ & 0.69 \\
& $-2.11^{(<0.001)}+1.10 \log (\mathrm{TN})^{(<0.001)}$ & 0.75 \\
& $-1.13^{(<0.001)}+1.02 \log (\mathrm{TN})^{(<0.001)}-0.32 \log \left(\mathrm{PGP} \times 10^{3}\right)^{(<0.001)}$ &
\end{tabular}

Only significant models are shown; the P value of the parameters are shown in superscript in parentheses.

in any of the climate regions. Only a small percentage (warm $0.7 \%$, intermediate $2.8 \%$, and cold $0 \%$ ) of these benthic fish is known to feed on sediment or organisms herein.

\section{Discussion}

Our study shows that submerged vegetation can have a marked positive effect on local water clarity across all South American climate zones studied, with the notable exception of lakes where humic substance concentrations are high. From a comparison between entire lakes with and without abundant vegetation, the water clearing effect was less obvious. In the Northern Hemisphere, lakes with abundant vegetation are also often clearer in the open water than lakes of comparable trophic state without abundant vegetation (Jeppesen and others 1990). In the South American lakes, we did not find this systematic difference.

The interpretation of the (lack of) differences in water clarity between lakes with abundant and sparse vegetation at comparable trophic state is not straightforward. Vegetation may influence water clarity, but may affect nutrient (TN and TP) concentrations as well (for example, Carpenter 1980; Van Donk and others 1993). Although we did not see differences in water clarity at similar nutrient concentrations, the South American lakes with abundant vegetation may very well be clearer than their counterparts without vegetation while receiving similar nutrient loads. Furthermore, the relationship between water clarity and submerged vegetation works both ways: in more turbid water, 

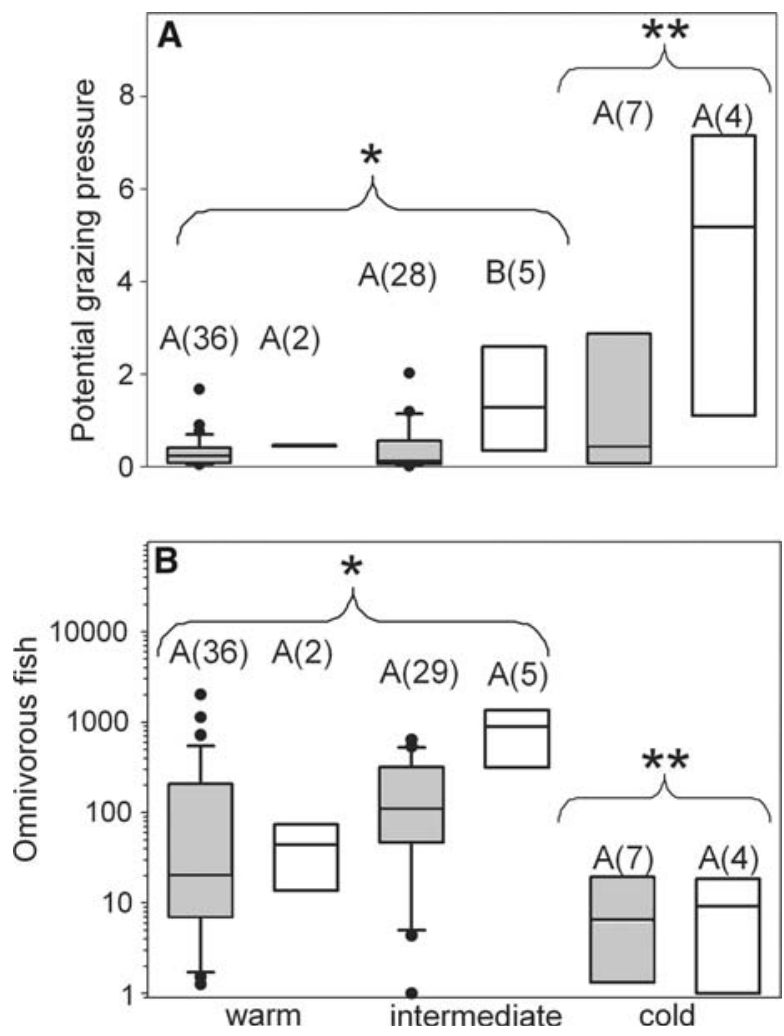

Figure 7. Potential grazing pressure (zooplankton:algal biomass ratio) (a) and CPUE (individuals net ${ }^{-1} \cdot 12 \mathrm{~h}$ ) of omnivorous fish (b) in different climate zones in lakes with scarce vegetation (PVI $<30 \%$, gray bars) and abundant vegetation (white). The stars indicate homogenous subsets for the climate zones (post hoc Tukey). See Figure 2 for more details.

it is less likely to find abundant vegetation. The critical turbidity at which submerged macrophytes disappear, however, may vary with climate; presumed low periphyton shading (for example, Meerhoff and others 2007a; Kosten and others 2009b), high irradiances, and strong water level fluctuations (Bécares and others 2008) may lead to a higher persistence of submerged vegetation at higher turbidities in some climates.

Different mechanisms could account for the apparent similarity in water clarity in South American lakes with and without abundant vegetation. Fish community composition may play an important role. In North European lakes, the percentage of piscivorous fish is generally high in oligotrophic-mesotrophic lakes, whereas with an increase in TP, catches of cyprinids increase strongly (Jeppesen and others 2000). Bream, Abramis brama, has an important share in the fish community in these TP-rich and vegetation-poor lakes causing resuspension of sediment due to bioturbation (Lammens 1989). In contrast, in the lakes studied here, a decrease in PVI did not coincide with a decrease in the proportion of piscivorous fish or with an increase in the proportion of benthic fish. Furthermore, we found no correlation between the CPUE of benthic fish and suspended OM, which may indicate that benthic fish do not bioturbate the sediment to the same extent as in North temperate lakes while feeding. This assumption is strengthened by the low share of benthic fish with diets based on (organisms in the) sediment, which would require bioturbating foraging activities. This may imply that the turbidity in the vegetation-poor lakes studied here is not further increased through bioturbation by the fish population. Experimental research is needed to substantiate this hypothesis.

Fish may also affect water clarity through predation on zooplankton. Depending on the fish density, diet and habitat preference, vegetation may provide a refuge function for zooplankton (Schriver and others 1995; Perrow and others 1999; Romare and Hansson 2003; Romare and others 2005; Meerhoff and others 2007b). Our data confirmed this: we found that the potential grazing pressure of zooplankton on algae is generally higher in lakes with abundant submerged vegetation. Lakes with abundant vegetation in combination with low omnivorous fish densities had the highest potential grazing pressures. This combination mainly occurred in the cold climate zone (South Argentina). In the intermediate and warm lakes (Provincia de Buenos Aires in Argentina, Uruguay, and Brazil), the higher densities of omnivorous fish most likely impede the establishment of larger-sized zooplankton usually responsible for high grazing pressures (see also Jeppesen and others 2007a). A detailed analysis of the zooplankton taxa in the study lakes, furthermore, confirmed that fish are likely to be the main driver of zooplankton community size structure; whereas, the influence of vegetation seems limited (Lacerot and others unpublished data). In the warmer lakes, this is likely caused by strong fish zooplanktivory due to a combination of multiple or continuous reproductive events (van Leeuwen and others 2007), lower densities of large specialist piscivores (see also Quirós 1997), widespread omnivory (Branco and others 1997; Blanco and others 2003; Mazzeo and others unpublished data), and high fish densities (Teixeira-de Mello and others 2009). The lower grazing pressure in warmer lakes compared to colder lakes in South American concurs with findings in a European study (Gyllström and others 2005) and comparative studies of lakes in Europe and Florida (Havens and others 2009). 
Even though the grazing pressure in lakes in the intermediate and warm climate region is lower than in the cold lakes, overall the potential grazing pressure is often higher in lakes with abundant vegetation when compared to lakes with scarce vegetation within the same climate region. The potential grazing pressure positively influences the water transparency and negatively influences organic matter and chla concentrations, indicating an indirect water clearing effect of the vegetation through zooplankton. The increase in water transparency due to top-down control of grazing on phytoplankton may be noticeable in the entire lake when zooplankton graze outside the vegetation beds or it may be more local when they mainly stay inside the beds. The estimated effect on phytoplankton biomass was highest in the coldest lakes where the potential grazing pressure was highest.

The local water clearing effect did not significantly differ among climatic regions, instead it varied strongly within each climatic zone. The effect was, however, generally lower than observed in a variety of Northern hemisphere temperate lakes where the water clearing effect ranged between $80 \%$ and $96 \%$ (Table 5.1 in Scheffer 1998). This difference may be caused either by differences in the refuge function for zooplankton (see also Meerhoff and others $2007 b)$ or by differences in vegetation taxa between the Northern hemisphere temperate lakes and the South American lakes studied here. Differences in morphology and biomass distribution among vegetation types may influence the water clearing effect through its effect on turbulence and sedimentation (Newall and Hughes 1995). A comparison of the water clearing effect of different vegetation taxa in the study lakes confirmed that taxa-specific variations exist, especially concerning the effect on phytoplankton.

In addition to the type of vegetation, the concentration of humic substances influences the water clearing effect of the vegetation. In lakes where humic substances contributed relatively much to water transparency, vegetation cleared the water very little. In some cases, transparency was even lower inside than outside the vegetation beds. This may be explained by the fact that vegetation (together with organic soils) can be a major source of humic substances (Thurman 1985). Obviously, water clearing mechanisms, such as the promotion of grazing and sedimentation, do not influence humic substances.

Depending on the vegetation characteristics and the water composition, vegetation may thus en- hance water clarity by various degrees. By increasing the transparency, the vegetation positively influences the euphotic depth and thereby its potential colonization depth. Depending on the morphology of the lake, this may lead to the colonization of a large fraction of the lake area.

\section{FinAl Remarks}

Judged from a comparison of water clarity inside and outside vegetation beds, vegetation appeared to have a similar positive effect on the water clarity across all coastal plain lakes in the South American climate regions studied. From a comparison between entire lakes with and without abundant vegetation, the water clearing effect is less easily deduced. We found indications, however, that the key mechanism for alternative states to occur-that is, vegetation enhancing water clarity-also works in these South American lakes, albeit it may be less pronounced than in Northern hemisphere temperate lakes as also demonstrated in comparative studies of temperate Danish lakes and subtropical Florida lakes (Jeppesen and others 2007b). This may have implications for their management. Many restoration measures have been developed in temperate lakes and aim to increase vegetation growth to restore or stabilize the clear water state. Even though success is not guaranteed, measures such as vegetation transplantation or temporary lowering of the water level may therefore also be successful in other climatic regions, though the effect on clarity is expectedly lower. In humic lakes or lakes with a high density of omnivorous fish, these measures will have a small chance of success.

\section{ACKNOWLEDGMENTS}

We thank Tiago Finkler, Ruberto Fragoso Jr., Antônio R.T. Bueno (Universidade Federal do Rio Grande do Sul), Soledad García, Carolina Crisci, Valeria Perez, Franco Teixeira, and Guillermo Goyenola (Universidad de la República, Uruguay), Juan César Paggi and Susana Jose de Paggi (Instituto Nacional de Limnología, Argentina), Jose Luiz Attayde, Elinez Rocha, Fabrício Camacho, Jandeson Brasil, Rosemberg Menezes, Wanessa Sousa, Nils Okun, Michelle Medeiros, and Gabriela Moura (Universidade Federal do Rio Grande do Norte, Brazil), Alessandro Del'duca Teixeira, Carlos Duque Estrada, Felipe Siqueira Pacheco, Raquel Mendonça (Universidade Federal de Mina Gerais), Christina Castelo Branco, Leonardo Coimbra, José Henrique 
Cantarino Gomes (Universidade do Estado do Rio de Janeiro, Brazil), Vera Huszar, Luciana Silva da Costa, Marcio Braz, Uanderson Pereira de Jesus, senhor Geel (Museo Nacional, RJ), Miquel Lurling, John Beijer, and Frits Gillissen (Wageningen University), Susana Romo (Universitat de València), Patricia Mburucuyá and Juan Carrau, Korine Hengst, Judith Jobse, Willemijn Noordoven, Kees Kosten, and Ineke Kosten. We also express our gratitude to all lake owners and the lake shore inhabitants for providing access to the lake and sometimes much more. This research was financially supported by The Netherlands Organization for Scientific Research (NWO) Grant W84-549 and WB84-586, The National Geographic Society Grant 7864-5; in Brazil by Conselho Nacional de Desenvolvimento Científico e Tecnológico (CNPq) Grants 480122, 490409, 311427; in Uruguay by PEDECIBA, Maestría en Ciencias Ambientales, Donación Aguas de la Costa S.A., and Banco de Seguros del Estado. NM was supported by Sistema Nacional de Investigadores. EJ was supported by the EU FP6 project Eurolimpacs; CLEAR (a Villum Kann Rasmussen Centre of Excellence Project) and Galathea 3.

\section{OPEN ACCESS}

This article is distributed under the terms of the Creative Commons Attribution Noncommercial License which permits any noncommercial use, distribution, and reproduction in any medium, provided the original author(s) and source are credited.

\section{REFERENCES}

Appelberg M. 2000. Swedish standard methods for sampling freshwater fish with multi-mesh gillnets. Fiskerieverket Inf $1: 3-32$.

Bachmann RW, Horsburgh CA, Hoyer MV, Mataraza LK, Canfield DE. 2002. Relations between trophic state indicators and plant biomass in Florida lakes. Hydrobiologia 470:219-34.

Barko JW, James WF. 1998. Effects of submerged aquatic macrophytes on nutrient dynamics, sedimentation, and resuspension. In: Jeppesen E, Søndergaard M, Søndergaard M, Christoffersen K, Eds. The structuring role of submerged macrophytes in lakes. New York: Springer-Verlag. p 197-214.

Bécares E, Gomá J, Fernández-Aláez M, Fernández-Aláez C, Romo S, Miracle M, Ståhl-Delbanco A, Hansson L-A, Gyllström M, Van de Bund W, Van Donk E, Kairesalo T, Hietala J, Stephen D, Balayla D, Moss B. 2008. Effects of nutrients and fish on periphyton and plant biomass across a European latitudinal gradient. Aquat Ecol 42:561-74.

Blanco S, Romo S, Villena M-J, Martínez S. 2003. Fish communities and food web interactions in some shallow Mediterranean lakes. Hydrobiologia 506-509:473-80.
Branco CWC, Aguiaro T, Esteves FA, Caramaschi EP. 1997. Food sources of the Teleost Eucinostomus argenteus in two coastal lagoons of Brazil. Stud Neotrop Fauna Environ 32:33-40.

Buiteveld H. 1995. A model for calculation of diffuse light attenuation (PAR) and Secchi depth. Neth J Aquat Ecol 29:55-65.

Canfield DE, Shireman JV, Colle DE, Haller WT, Watkins CE, Maceina MJ. 1984. Prediction of chlorophyll a concentrations in Florida lakes importance of aquatic macrophytes. Can J Fish Aquat Sci 41:497-501.

Carpenter SR. 1980. Enrichment of Lake Wingra, Wisconsin USA, by submersed macrophyte decay. Ecology 61:1145-55.

Conrow R, Zale AV, Gregory RW. 1990. Distributions and abundances of early life stages of fishes in a Florida lake dominated by aquatic macrophytes. Trans Am Fish Soc 119:521-8.

De Lange HJ. 2000. The attenuation of ultraviolet and visible radiation in Dutch inland waters. Aquat Ecol 34:215-26.

Gillooly JF, Dodson SI. 2000. Latitudinal patterns in the size distribution and seasonal dynamics of new world, freshwater cladocerans. Limnol Oceanogr 45:22-30.

Gross EM, Sütfeld R. 1994. Polyphenols with algicidal activity in the submerged macrophyte Myriophyllum spicatum L. Acta Hortic 381:710-16.

Gyllström M, Hansson LA, Jeppesen E, Garcia-Criado F, Gross E, Irvine $\mathrm{K}$, Kairesalo T, Kornijow R, Miracle MR, Nykanen M, Noges T, Romo S, Stephen D, Van Donk E, Moss B. 2005. The role of climate in shaping zooplankton communities of shallow lakes. Limnol Oceanogr 50:2008-21.

Hansson LA, Johansson L, Persson L. 1987. Effects of fish grazing on nutrient release and succession of primary producers. Limnol Oceanogr 32:723-9.

Hasler AD, Jones E. 1949. Demonstration of the antagonistic action of large aquatic plants on algae and rotifers. Ecology $30: 346-59$

Havens KE, Elia AC, Taticchi MI, Fulton RSIII. 2009. Zooplankton-phytoplankton relationships in shallow subtropical versus temperate lakes Apopka (Florida, USA) and Trasimeno (Umbria, Italy). Hydrobiologia 628:165-75.

Hilt S, Gross EM, Hupfer M, Morscheid H, Mählmann J, Melzer A, Poltz J, Sandrock S, Scharf E-M, Schneider S, van de Weyer K. 2006. Restoration of submerged vegetation in shallow eutrophic lakes-a guideline and state of the art in Germany. Limnol Ecol Manag Inland Waters 36:155-71.

Hudon C, Lalonde S, Gagnon P. 2000. Ranking the effects of site exposure, plant growth form, water depth, and transparency on aquatic plant biomass. Can J Fish Aquat Sci 57:31-42.

Jeppesen E, Jensen JP, Kristensen P, Søndergaard M, Mortensen E, Sortkjær O, Olrik K. 1990. Fish manipulation as a lake restoration tool in shallow, eutrophic, temperate lakes 2: threshold levels, long-term stability and conclusions. Hydrobiologia 200-201:219-28.

Jeppesen E, Søndergaard M, Kanstrup E, Petersen B. 1994. Does the impact of nutrients on the biological structure and function of brackish and freshwater lakes differ. Hydrobiologia 276:15-30.

Jeppesen E, Lauridsen TL, Kairesalo T, Perrow MR. 1998. Impact of submerged macrophytes on fish-zooplankton interactions in lakes. In: Jeppesen E, Søndergaard M, Søndergaard M, Christoffersen K, Eds. The structuring role of submerged macrophytes in lakes. New York: Springer-Verlag. p 91-114. 
Jeppesen E, Jensen JP, Søndergaard M, Lauridsen T. 1999. Trophic dynamics in turbid and clearwater lakes with special emphasis on the role of zooplankton for water clarity. Hydrobiologia 409:217-31.

Jeppesen E, Peder Jensen J, Sondergaard M, Lauridsen T, Landkildehus F. 2000. Trophic structure, species richness and biodiversity in Danish lakes: changes along a phosphorus gradient. Freshw Biol 45:201-18.

Jeppesen E, Søndergaard M, Mazzeo N, Meerhoff MCB, Huszar V, Scasso F. 2005. Lake restoration and biomanipulation in temperate lakes: relevance for subtropical and tropical lakes. In: Reddy MV, Ed. Restoration and management of tropical eutrophic lakes. Enfield: Science Publishers. p 34159.

Jeppesen E, Meerhoff M, Jacobsen B, Hansen R, Søndergaard M, Jensen J, Lauridsen T, Mazzeo N, Branco C. 2007a. Restoration of shallow lakes by nutrient control and biomanipulation-the successful strategy varies with lake size and climate. Hydrobiologia 581:269-85.

Jeppesen E, Søndergaard M, Meerhoff M, Lauridsen T, Jensen J. 2007b. Shallow lake restoration by nutrient loading reduction-some recent findings and challenges ahead. Hydrobiologia 584:239-52.

Jones RC. 1990. The effect of submersed aquatic vegetation on phytoplankton and water quality in the tidal freshwater Potomac River, USA. J Freshw Ecol 5:279-88.

Kosten S, Huszar VLM, Mazzeo N, Scheffer M, Sternberg LdSL, Jeppesen E. 2009a. Lake and watershed characteristics rather than climate influence nutrient limitation in shallow lakes. Ecol Appl 19(7):1791-1804.

Kosten S, Kamarainen A, Jeppesen E, van Nes EH, Peeters ETHM, Mazzeo N, Sass L, Hauxwell J, Hansel-Welch N, Lauridsen TL, Søndergaard M, Bachmann RW, Lacerot G, Scheffer M. 2009b. Climate-related differences in the dominance of submerged macrophytes in shallow lakes. Global Change Biol. doi:10.1111/j.1365-2486.2009.01969.x.

Lammens EHRR. 1988. Trophic interactions in the hypertrophic Lake Tjeukemeer (Netherlands): top-down and bottom-up effects in relation to hydrology, predation and bioturbation during the period 1974-1985. Limnologica 19:81-6.

Lammens E. 1989. Causes and consequences of the success of bream in Dutch eutrophic lakes. Aquat Ecol 23:11-18.

Madsen JD, Chambers PA, James WF, Koch EW, Westlake DF. 2001. The interaction between water movement, sediment dynamics and submersed macrophytes. Hydrobiologia 444:71-84.

Mazumder A, Taylor WD, McQueen DJ, Lean DR, Lafontaine NR. 1990. A comparison of lakes and lake enclosures with contrasting abundances of planktivorous fish. J Plankton Res 12:109-24.

Mazzeo N, Rodriguez-Gallego L, Kruk C, Meerhoff M, Gorga J, Lacerot G, Quintans F, Loureiro M, Larrea D, Garcia-Rodriguez F. 2003. Effects of Egeria densa Planch beds on a shallow lake without piscivorous fish. Hydrobiologia 506:591-602.

Meerhoff M, Clemente JM, de Mello FT, Iglesias C, Pedersen AR, Jeppesen E. 2007a. Can warm climate-related structure of littoral predator assemblies weaken the clear water state in shallow lakes? Global Change Biol 13:1888-97.

Meerhoff M, Iglesias C, De Mello FT, Clemente JM, Jensen E, Lauridsen TL, Jeppesen E. 2007b. Effects of habitat complexity on community structure and predator avoidance behaviour of littoral zooplankton in temperate versus subtropical shallow lakes. Freshw Biol 52:1009-21.
Meijer ML, Hosper SH. 1997. Effects of biomanipulation in the large and shallow Lake Wolderwijd, The Netherlands. Hydrobiologia 342:335-49.

Moss B. 1990. Engineering and biological approaches to the restoration from eutrophication of shallow lakes in which aquatic plant communities are important components. Hydrobiologia 200-201:367-77.

New M, Lister D, Hulme M, Makin I. 2002. A high-resolution data set of surface climate over global land areas. Clim Res 21:1-25.

Newall AM, Hughes JMR. 1995. Microflow environments of aquatic plants in flowing water wetlands. In: Hughes JMR, Heathwaite AL, Eds. Hydrology and hydrochemistry of British wetlands. Chichester: Wiley. p 363-81.

NNI. 1986. Water-photometric determination of the content of dissolved orthophosphate and the total content of phosphorous compounds by continuous flow analysis. Normcommissie 390147 "Waterkwaliteit", Nederlands Normalisatie-insituut, p 8.

NNI. 1990. Water-photometric determination of the content of ammonium nitrogen and the sum of the contents of ammoniacal and organically bound nitrogen according to Kjeldahl by continuous flow analysis. Nederlands Normalisatie-insituut, Normcommissie 390147 "Waterkwaliteit", p 8.

Nusch E. 1980. Comparison of different methods for chlorophyll and phaeopigments determination. Arch Hydrobiol Beiheft Ergeb Limnol 14:14-36.

Ozimek T, Gulati RD, Van Donk E. 1990. Can macrophytes be useful in biomanipulation of lakes-the Lake Zwemlust example. Hydrobiologia 200:399-407.

Perrow M, Jowitt A, Stansfield J, Phillips G. 1999. The practical importance of the interactions between fish, zooplankton and macrophytes in shallow lake restoration. Hydrobiologia 395396:199-210.

Pokorny J, Kvet J, Ondok JP, Toul Z, Ostry I. 1984. Productionecological analysis of a plant community dominated by Elodea canadensis. Aquat Bot 19:263-92.

Quirós R. 1997. Fish effects on trophic relationships in the pelagic zone of lakes. Hydrobiologia 361:101-11.

Romare P, Hansson L-A. 2003. A behavioral cascade: top-predator induced behavioral shifts in planktivorous fish and zooplankton. Limnol Oceanogr 48:1956-64.

Romare P, Schindler DE, Scheuerell MD, Scheuerell JM, Litt AH, Shepherd JH. 2005. Variation in spatial and temporal gradients in zooplankton spring development: the effect of climatic factors. Freshw Biol 50:1007-21.

Sazima I, Zamprogno C. 1985. Use of water hyacinths as shelter, foraging place, and transport by young piranhas, Serrasalmus spilopleura. Environ Biol Fish 12:237-40.

Scheffer M. 1990. Multiplicity of stable states in freshwater systems. Hydrobiologia 200-201:475-86.

Scheffer M. 1998. Ecology of shallow lakes. London: Chapman and Hall.

Scheffer M, Hosper SH, Meijer ML, Moss B, Jeppesen E. 1993. Alternative equilibria in shallow lakes. Trends Ecol Evol 8:275-9.

Schriver P, Bøgestrand J, Jeppesen E, Søndergaard M. 1995. Impact of submerged macrophytes on fish-zooplankton-phytoplankton interactions: large-scale enclosure experiments in a shallow eutrophic lake. Freshw Biol 33:255-70.

Søndergaard M, Bruun L, Lauridsen T, Jeppesen E, Vindbæk MT. 1996. The impact of grazing waterfowl on submerged 
macrophytes: in situ experiments in a shallow eutrophic lake. Aquat Bot 53:73-84.

Teixeira-de Mello F, Meerhoff M, Pekcan-Hekim Z, Jeppesen E. 2009. Substantial differences in littoral fish community structure and dynamics in subtropical and temperate shallow lakes. Freshw Biol 54:1202-15.

Thurman EM. 1985. Organic geochemistry of natural waters. Boston: Martinus Nijhoff/Dr W. Junk Publishers.

Timms RM, Moss B. 1984. Prevention of growth of potentially dense phytoplankton populations by zooplankton grazing, in the presence of zooplanktivorous fish, in a shallow wetland ecosystem. Limnol Oceanogr 29:472-86.

Van Donk E, Gulati RD, Iedema A, Meulemans JT. 1993. Macrophyte-related shifts in the nitrogen and phosphorus contents of the different trophic levels in a biomanipulated shallow lake. Hydrobiologia 251:19-26.

van Leeuwen E, Lacerot G, van Nes EH, Hemerik L, Scheffer M. 2007. Reduced top-down control of phytoplankton in warmer climates can be explained by continuous fish reproduction. Ecol Model 206:205-12. 